ORIGINAL ARTICLE

\title{
An investigation into the short term and medium term health impacts of personal incapacitant sprays. A follow up of patients reported to the National Poisons Information Service (London)
}

\author{
E Euripidou, R MacLehose, A Fletcher
}

Emerg Med J 2004;21:548-552. doi: 10.1136/emj.2003.012773

Objectives: The aim of this study is to describe the pattern of ill health after personal incapacitant spray (PIS) exposures reported to the National Poisons Information Service-London (NPIS-L) and the Chemical Incident Response Service and to evaluate the relation between sub-categories of PIS exposure and adverse health effects.

Methods: Case series study of patients reported to the NPIS-L, by attending medical personnel during the period 16 January to 31 September 1998. Data collected by questionnaire sent to these medical personnel.

See end of article for authors' affiliations

Results: Several "adverse" symptoms, particularly dermatitis and blisters were reported for cases exposed to police PIS. These cases were more frequent than in those people exposed to non-police PIS. Adverse effects occurring more than six hours after exposure were also observed, which is in conflict with the

Correspondence to: Mr E Euripidou, Medical Toxcicology Unit, Avonley Road, London SÉ14 5ER, UK; reuripidou@ hotmail.com recorded immediate, short lived, and self limiting symptoms that PIS are designed to cause. Most patients with persisting symptoms required further treatment.

Conclusions: These findings suggest that the formulation of CS (o-chlorobenzylidine malononitrile) with MiBK (methyl iso-butyl ketone) used by the police is more harmful that has been previously assumed. If confirmed then the continued use of this formulation should be reviewed because of longer duration of Accepted for publication 13 February 2004 adverse effects. Less concentrated formulations may reduce the severity or persistence of the adverse effects.

$M$ ost UK police forces now use hand held CS spray canisters containing O-chlorobenzylidine malononitrile dissolved in the solvent methyl iso-butyl ketone (MiBK). In 1996 the National Poisons Information ServiceLondon (NPIS-L) received over 750 emergency personal incapacitant spray (PIS) incident inquiries. This figure probably represents a small fraction of total PIS incidents reported in the UK as the NPIS-L is only usually contacted if advice on patient management is required. ${ }^{1}$

English and Welsh police forces have progressively adopted use of CS spray since 1995. It is used for self defence in situations where lethal force is inappropriate. Its use has been sanctioned by the Association of Chief Police Officers. ${ }^{2}$

PIS agents including mace and pepper spray are illegal in the UK and classed as prohibited weapons, but can be purchased and illegally imported from elsewhere in the EU and North America where they are commercially available.

In 1928 B B Corson and R W Stoughton developed CS as a white crystalline powder. The agent was originally designed for use in grenades where CS aerosols are pyrotechnically liberated from solid CS. However, the hand held CS spray in canisters used by UK police forces is dispersed in a liquid tht may adhere to the person sprayed and thus acts differently. ${ }^{3}$ CS aerosol produces an almost immediate irritation. It is designed to incapacitate targeted people by making them incapable of any concerted resistance. Generally symptoms should subside within 30-60 minutes of exposure. ${ }^{4}$

CS causes a burning sensation in the eyes and is a potent lacrimator, but generally does not cause irreversible eye effects. $^{5}$ Duration of aerosol induced irritation is usually 5-15 minutes after removal from exposure. Respiratory effects include coughing, bronchoconstriction, and change in the frequency and depth of breathing. ${ }^{6}$

Parneix-Spake et al reported cases of CS spray causing erythematous dermatitis and allergic contact dermatitis with vesicles, keratitis, blisters and crusts, accompanied by pronounced oedema. ${ }^{7}$ Onset occurred 12 hours to three days after exposure. ${ }^{7-9}$ Varma and Holt report a case of severe contact dermatitis. ${ }^{10}$ Further case reports record delayed effects with various types of dermatitis and blisters. ${ }^{11-15}$

No deaths have been attributed to CS. ${ }^{5}$ However, Hu et al reported that inhalation of high concentration CS could result in chemical pneumonitis and fatal pulmonary oedema. ${ }^{16}$ However, the $\mathrm{LD}_{50}$ of inhaled $\mathrm{CS}$ gas has been estimated at 25000 to $150000 \mathrm{mg} / \mathrm{m}^{3}$ — that is, a dose many times greater than the exposure dose that produces intolerable symptoms in humans. ${ }^{16-18}$ No site decontamination other than ventilation is necessary after use of CS aerosol because CS dispersed in air quickly loses potency. ${ }^{5}$

MiBK is a solvent and a denaturant with many commercial applications. MiBK is absorbed dermally and is of low oral toxicity. The serum half life and total clearance time for parent MiBK is estimated at 66 minutes and six hours in guinea pigs respectively. ${ }^{19}$ Dermal exposure may cause only minimal irritation unless sprayed in close proximity of skin. ${ }^{20}$ Prolonged dermal contact may cause irritation, defatting of the skin, flaking and peeling. ${ }^{19}{ }^{20}$ Eye irritation and pain may follow exposure to MiBK vapour or liquid. ${ }^{21}$ Dizziness, headache, drowsiness, ataxia, nausea, vomiting,

Abbreviations: NPIS-L, National Poisons Information Service (London); PIS, personal incapacitant spray 
weakness, and loss of appetite have also been reported after exposure. ${ }^{19-21}$ There have been no epidemiological studies after the use of PIS with the solvent MiBK under field conditions. $^{22}$

Acceptance of the CS spray incapacitant by the UK police research group was to a large extent based on safety data collected in France and in the United States, and by the Chemical Warfare Research (formerly the Chemical Research Establishment) establishment at Porton Down. ${ }^{23}$ However, US studies may not be applicable in determining the safety of current CS spray use in Britain because the composition of the CS spray used in the UK differs significantly from that used in the United States. ${ }^{23}$ The UK spray contains 5\% CS dissolved in MiBK, released in a $5 \mathrm{cl}$ burst whereas the US spray contains only $1 \%$ CS dissolved in MiBK, released in a 1 cl burst, a 25-fold smaller dose. ${ }^{32}$

Police trials for trainers of CS spray began in spring 1995 but were temporarily suspended because one of the volunteer police officers sprayed suffered severe eye burns requiring hospitalisation. ${ }^{24}$ Officers reported 754 incidents over the trial period and areas where CS was used, and 381 incidents in which CS was drawn but not used. By using these figures it was estimated that an officer carrying CS would draw their canister about four times every year but use it only once every 32 months. $^{24}$

The objectives for the case series review was to characterise the pattern of ill health diagnosed by the treating medical personnel and to assess if the pattern differed between "police" and "non-police" related PIS exposure.

\section{METHODS}

\section{Data collection}

A prospective case series was undertaken based on all PIS incidents reported to the NPIS-L between 16 January 1998 and 31 September 1998. A questionnaire was designed, piloted, and circulated to medical personnel who made the initial PIS inquiry to the NPIS-L. The questionnaire gathered data on patient characteristics, PIS identity, details surrounding exposure, health effects after exposure, and information on treatment given. Non-responders were followed up on two occasions by letter and telephone.

\section{Sample size and response rate}

Altogether 277 PIS incidents reported to NPIS-L were followed up by sending a questionnaire to the person that had contacted NPIS-L. The response rate was 60\%, 166 returned questionnaires of which $14 \%$ (24) questionnaires were returned incomplete, in which cases NPIS-L data collected at the time of the initial clinical inquiry were used to code as much of the questionnaire as possible. However, the overall questionnaire return total was greater because an additional 28 questionnaires were completed for previously not reported PIS incidents and some incidents included more than one person. A total of 194 returned questionnaires were included in the analysis.

\section{Data handling and entry \\ Definition of the main exposure variable}

Respondents were asked to identify the type of PIS to which patients were exposed. The type of PIS could not always be identified, therefore a further question sought information about the circumstances of exposure. By means of these two questions, the exposure could be classified with a good degree of certainty into whether the CS spray was delivered by the police or not. Analysis comparing police and nonpolice PIS are restricted to the subset that could be classified with some confidence.

\section{Statistical analysis}

Stata (release 4, Stata Corporation, College Station, TX) and EpiInfo (version 6, Centers for Disease Control and Prevention, Atlanta, GA) were used for all statistical analysis. Binomial models investigated the association between exposure to a police PIS and the risk of various symptoms or conditions. Comparisons of symptom frequency between the two exposure groups were adjusted for age, sex, preexisting asthma and eczema, time from exposure to treatment, and whether or not the patient was exposed directly or exposed indirectly as a bystander.

\section{RESULTS}

Of the 194 PIS incidents analysed, the circumstances of exposure were identified in 152 instances. Table 1 shows baseline characteristics for these 152 people. The mean age of the study population was 26.3 years $(1-54), 22$ incidents involved those 18 years or under. Those aged under the age of 11 are likely to have been bystanders-no further information is available on these cases. Seventy seven per cent of incidents involved males. Sixty one per cent (93) of these 152 incidents were positively identified as police related. The remainder are considered not to have been sprayed by police.

Data on the time from PIS exposure and consultation with a medical professional were recorded. Time to consultation may be an indicator for delayed or prolonged effects of the PIS. Those attending immediately were less likely to be police sprayed than those attending later. Of the PIS exposed patients seeking medical advice more than six hours after exposure, $84 \%$ had been exposed to a police PIS, compared with only $51 \%$ of those seeking attention less than six hours after exposure $(p \leqslant 0.001)$. This contrast may reflect the circumstances rather than severity, if for example, arrest or fear of arrest led to a delay in seeking treatment. However this remains significant as PISs are designed to have short lived and self limiting effects. Police recommend that people who have been taken into custody after being sprayed should be issued with replacement clothes to reduce recontamination. The proportion requiring treatment after exposure was similar in both those exposed to police and non-police PISs.

The route of exposure in all PIS incidents was also recorded. Exposure via the eye (53\%) and the face $(54 \%)$ were the most common routes (multiple routes were recorded). However, in $31 \%$ (35) of cases the exposure route was via inhalation. This warrants further investigation.

Respondents were asked to describe symptoms at both the time of exposure and at the time of consultation, together with any diagnoses. Table 2 summarises the symptoms for the 93 police PIS cases.

The most common immediate symptoms reported were lachrymation, burning sensation, and blurred vision. At consultation a lower percentage reported lachrymation and burning sensations though this was still reported by over $20 \%$ of cases.

Table 3 shows the most common symptoms and diagnoses reported at the time of consultation for all PIS incidents with the breakdown by type of spray. Lachrymation and a burning sensation were again the most common symptoms, however it is of concern that again uncommon conditions such as erythematous dermatitis, conjunctivitis, blisters, and oedema were observed.

The two conditions that were significantly associated with type of spray were also significantly most prevalent among those exposed to police spray: erythematous dermatitis and blisters.

An adverse reaction was defined as a patient diagnosed or reporting one or more of; erythematous dermatitis, allergic contact dematitis with or without vesicles or blisters, or, lachrymation, blurred vision, conjunctivitis, oedema, 
Table 1 Baseline characteristics of the study population

\begin{tabular}{|c|c|c|c|c|}
\hline Explanatory variables & $n=152$ & $\begin{array}{l}\text { Not sprayed by police } \\
\text { number }(\%)\end{array}$ & $\begin{array}{l}\text { Sprayed by police } \\
\text { number (\%) }\end{array}$ & $\begin{array}{l}\text { p Value for association } \\
\text { between characteristic } \\
\text { and spray type }\end{array}$ \\
\hline \multicolumn{5}{|l|}{ Age groups (y) } \\
\hline$<11$ & 11 & $8(29)$ & $3(5)$ & \\
\hline $12-18$ & 11 & $7(25)$ & $4(7)$ & - \\
\hline $19-25$ & 17 & $7(25)$ & $10(18)$ & - \\
\hline $26-36$ & 31 & $6(21)$ & $25(45)$ & - \\
\hline $37-46$ & 9 & 0 & $9(16)$ & - \\
\hline $47+$ & 5 & 0 & $5(9)$ & - \\
\hline${ }^{*}$ Age missing & 68 & & & \\
\hline \multicolumn{5}{|l|}{ Sex } \\
\hline Female & 28 & $10(23)$ & $18(22.5)$ & \\
\hline Male & 96 & 34 (77) & $62(77.5)$ & $p=0.84$ \\
\hline${ }^{*}$ Sex missing & 28 & & & \\
\hline \multicolumn{5}{|c|}{ Directly exposed to PIS } \\
\hline No & 43 & 19 (32.7) & $24(25.8)$ & \\
\hline Yes & 87 & $35(60)$ & $52(55.9)$ & $p=0.97$ \\
\hline Not known & 21 & $4(7)$ & 17 (18) & $p=0.11$ \\
\hline${ }^{*}$ Missing & 1 & & & \\
\hline \multicolumn{5}{|l|}{$\begin{array}{l}\text { Time from exposure to } \\
\text { consultation }\end{array}$} \\
\hline$<1$ hour & 34 & $22(40)$ & $12(14)$ & \\
\hline$>1$ hour & 108 & $33(60)$ & $75(86)$ & $p \leqslant 0.001$ \\
\hline${ }^{*} M i s s i n g$ & 10 & & & \\
\hline \multicolumn{5}{|c|}{$\begin{array}{l}\text { Time from exposure to } \\
\text { consultation }\end{array}$} \\
\hline$<6$ hours & 98 & 48 (87) & 50 (57) & \\
\hline$>6$ hours & 44 & $7(13)$ & $37(43)$ & $p \leqslant 0.001$ \\
\hline${ }^{*}$ Missing & 10 & & & \\
\hline
\end{tabular}

shortness of breath, and a burning sensation one hour or larger after PIS exposure. Exposure categories were compared for adverse reactions after exposure. The group exposed to police PIS was more likely to experience an adverse outcome $(\mathrm{p}=0.002)$.

Of 148 incidents, where the exposure classification and the referral data are known, a higher percentage of police spray incidents were referred for further specialist treatment. This did not reach statistical significance.

The above comparisons have been adjusted for potential confounding by age, sex, pre-existing asthma and eczema, time from exposure to treatment, and whether or not the patient was exposed directly. Their role as confounding factors in the association between adverse outcomes and police spray was assessed by including them in turn in the analyses and observing the effect on the odds ratios.

Sex and age had a moderate confounding effect on the association between exposure to a police PIS and suffering an adverse outcome. Neither pre-existing asthma, eczema, previous experience of PIS had a confounding effect. The relation remained statistically significant after adjusting for all these variables, the adjusted odds ratio being: (OR 7.44; 1.17 to $47.15 ; \mathrm{p}=0.01)$. Adding time from exposure to treatment changed the association but as noted above, time from treatment may be a consequence of police involvement as well as being an indicator of severity of delayed effects (OR $2.90 ; 1.08$ to $5.93 ; \mathrm{p}=0.03$ )

\section{Limitations of the study}

The applicability of the results of this study to the wider population may be limited as it is possible that not all people experiencing symptoms after exposure to a PIS will present for treatment, resulting in an overestimation of the proportion of exposed people seeking treatment. Only some of these are notified to the NPIS-L. It is also conceivable that a different selection (related to severity) operates for those presenting who have had an altercation with the police.

A weakness of this study is that it relies on physicians recall and completeness of hospital and NPIS-L records. Not all signs and symptoms may have been remembered or indeed recorded. Police related incidents may be better recorded because of possible litigation. While we cannot rule it out, we have no reason to suppose this recall would vary between categories of PIS. Exposure is more problematic: patients may not be exposed to PIS alone and clinical effects may be attributable to other agents. Also in interpreting these

Table 2 Total clinical effects of police spray in 1998 in 93 incidents reported to NPIS-L

\begin{tabular}{lll}
\hline Clinical effects & $\begin{array}{l}\text { Number (\%) symptoms reported } \\
\text { at time of exposure }\end{array}$ & $\begin{array}{l}\text { Number (\%) symptoms reported } \\
\text { at time of consultation }\end{array}$ \\
\hline Asymptomatic & $2(2.4)$ & $7(6.8)$ \\
Lachrymation & $30(37)$ & $21(20.5) \dagger$ \\
Blurred vision & $9(11)$ & $10(9.8)$ \\
Blisters & $3(3.7)$ & $15(14.7) \dagger$ \\
Shortness of breath & $6(7.4)$ & $5(4.9)$ \\
Burning sensations & $25(30.8)$ & $25(24.9)$ \\
*Others & $6(7.4)$ & $19(18.6) \ddagger$ \\
\hline$*$ Includes symptoms (redness, sore throat, stinging eyes, pain, photophobia, nose bleed, vomiting, nausea). \\
†p=0.01; $\neq p=0.02$, difference for two proportions.
\end{tabular}




\begin{tabular}{|c|c|c|c|c|c|}
\hline Symptoms & $\begin{array}{l}\text { Total }(\mathbf{n}) \text { of all } \\
\text { PIS incidents }\end{array}$ & $\begin{array}{l}\text { Not sprayed by } \\
\text { police, number (\%) }\end{array}$ & $\begin{array}{l}\text { Sprayed by police, } \\
\text { number }(\%)\end{array}$ & $\begin{array}{l}\text { Unadjusted odds ratio } \\
(95 \% \mathrm{CI})\end{array}$ & $\begin{array}{l}\text { p Value (Yates's } \\
\text { corrected) }\end{array}$ \\
\hline \multicolumn{6}{|c|}{ Lachrymation } \\
\hline No & 116 & $37(64)$ & $68(76)$ & 1 & \\
\hline Yes & 44 & $21(36)$ & $21(24)$ & 0.54 (0.26 to 1.13 ) & $p=0.09$ \\
\hline \multicolumn{6}{|c|}{ Blurred vision } \\
\hline No & 144 & $54(93)$ & 79 (99) & 1 & \\
\hline Yes & 16 & $4(7)$ & $10(11)$ & 1.70 (0.50 to 5.77$)$ & $p=0.38$ \\
\hline \multicolumn{6}{|c|}{ Conjunctivitis } \\
\hline No & 137 & $48(83)$ & $83(93)$ & 1 & \\
\hline \multicolumn{6}{|c|}{ Erythematous } \\
\hline No & 123 & $54(93)$ & $57(64)$ & 1 & \\
\hline Yes & 37 & $4(7)$ & $32(36)$ & 7.57 (2.34 to 24.51$)$ & $p \leqslant 0.001$ \\
\hline \multicolumn{6}{|l|}{ Blisters } \\
\hline No & 143 & $56(97)$ & $74(83)$ & 1 & \\
\hline Yes & 17 & 2 (3) & $15(17)$ & 5.67 (1.20 to 26.84$)$ & $p=0.01$ \\
\hline \multicolumn{6}{|l|}{ Oedema } \\
\hline No & 154 & $57(98)$ & $84(94)$ & 1 & \\
\hline Yes & 6 & $1(2)$ & $5(6)$ & 3.39 (0.37 to 30.34$)$ & $p=0.24$ \\
\hline \multicolumn{6}{|c|}{ Shortness of breath } \\
\hline No & 149 & $53(91)$ & $83(93)$ & 1 & \\
\hline Yes & 11 & $5(9)$ & $6(7)$ & $0.76(0.22$ to 2.65$)$ & $p=0.67$ \\
\hline \multicolumn{6}{|c|}{ Burning sensation } \\
\hline No & 120 & $43(74)$ & $64(72)$ & 1 & \\
\hline Yes & 40 & $15(26)$ & $25(28)$ & 1.12 (0.52 to 2.37 ) & $p=0.76$ \\
\hline \multicolumn{6}{|c|}{1.12 (0.02 10.001} \\
\hline No & 126 & $45(78)$ & $70(79)$ & 1 & \\
\hline Yes & 34 & $13(22)$ & $19(21)$ & 0.94 (0.42 to 2.09$)$ & $p=0.87$ \\
\hline \multicolumn{6}{|c|}{ Adverse outcome } \\
\hline No & 58 & $30(52)$ & $24(27)$ & 1 & \\
\hline & 102 & $28(48)$ & $65(73)$ & 2.90 (1.41 to 5.97 ) & $p=0.002$ \\
\hline \multicolumn{6}{|c|}{$\begin{array}{l}\text { Referred for further treatment to another } \\
\text { specialist department }\end{array}$} \\
\hline No & 57 & $36(63)$ & $43(47)$ & 1 & \\
\hline Yes & 91 & $21(37)$ & $48(53)$ & 1.91 (0.96 to 3.08 ) & $p=0.06$ \\
\hline
\end{tabular}

data we assume that all (and only) the police incidents involve the CS/MiBK mixture. More generally, case series studies have limited potential to test for the presence of valid statistical associations. ${ }^{25}$

\section{DISCUSSION}

Our initial findings show that delayed adverse effects attributable to police use of PIS are occurring. These are persisting several hours after exposure and this seems to contradict the assessments of Himsworth and others. ${ }^{4} 51718$ These delayed effects may be more common in those exposed to police PIS than non-police sprays. We have found evidence that some difference in symptoms exists between exposure to police spray and other PIS reported at the time of consultation, with a significantly higher risk of erythematous dermatitis and blisters in the police PIS incidents.

There was a significant increased risk of adverse effects in those exposed to police spray compared with non-police spray and this remained significant after adjustment for several potential confounders.

A higher proportion of those exposed to police spray sought medical advice six or more hours after exposure compared with those exposed to non-police spray. This may be attributable to confounding effects of the circumstances at exposure, delayed symptoms and signs that occur despite the published data that effects are short lived.

\section{CONCLUSIONS}

Several "adverse" symptoms, particularly dermatitis and blisters have been reported for cases exposed to police PIS, more so than for cases exposed to non-police PIS. Adverse effects more than six hours after exposure have also been observed, which is in conflict with the reported immediate, short lived, and self limiting symptoms that PIS are reported to cause. Most patients with persisting symptoms were referred for further treatment.

This study suggests that the CS preparation used by the UK police may cause more adverse effects than other PIS preparations. A detailed study is now required into the potential adverse effects of the CS used by police. The effectiveness and adverse effects of less concentrated or differently formulated CS gas may also need to be reviewed.

\section{ACKNOWLEDGEMENTS}

We would like to acknowledge the help and advice from Henrietta Wheeler and Virginia Murray in the preparation and writing up of this study.

\section{Authors' affiliations}

E Euripidou, R MacLehose, A Fletcher, Medical Toxicology Unit, London, UK

Funding: none.

Conflicts of interest: none declared.

\section{REFERENCES}

1 Volans GN, Wiseman HM. Surveillance of poisons - the role of poison control centres. In: Eylenbosch WJ, Noah NI, eds. Surveillance in health and disease. Oxford: OUP, 1988

2 Cambell D. User friendly can with a nasty sting. Guardian 1992 Jul 4;12.

3 Jones GRN. Are CS sprays safe? Lancet 1997;350:605-6.

4 Folb P, Talmund J. Tear gas - its toxicology and suggestions for management of its acute effects in man. S Afr Med J 1989;76:295.

5 Danto BL. Medical problems and criteria regarding the use of tear gas by police. Am J Forensic Med Pathol 1987;8:317-22. 
6 Cole TJ, et al. Ventilation, cardiac frequency and pattern of breathing during exercise in men exposed to o-chlorobenzylidine malononitrile (CS) and ammonia gas in low concentrations. Q J Exp Physiol 1977;62:341-51.

7 Parneix-Spake A, Theisen A, Roujeau JC, et al. Severe cutaneous reactions to self-defense sprays. Arch Dermatol 1993;129:913.

8 Leenutaphong V, Goerz G. Allergic contact dermatitis from c chloroacetophenone (tear gas). Contact Dermatitis 1989;20:316.

9 Ro YS, Lee CW. Tear gas dermatitis. Allergic contact sensitization due to CS. Int J Dermatol 1991;30:576-7.

10 Varma S, Holt PJA. Severe cutaneous reaction to CS gas. Clin Exp Dermatol 2001;26:248-50.

11 Sommer S, Wilkinson SM. Exposure-pattern dermatitis due to CS gas. Contact Dermatitis 1999;40:46.

12 Anonymous. Safety of chemical batons. [Editorial]. Lancet 1998;352:159.

13 Hill A, Ross M, Silverberg CM, et al. Medical hazards of the tear gas CS: a case of persistent, multisystem, hypersensitivity reaction and review of the literature. Medicine 2000;79:4, 234-40.

14 Weir $E$. The health impacts of crowd control agents. CMAJ 2001;164:15

15 Richard J, Thomas MC, Phillip A, et al. Acute pulmonary effects from ochlorobenzylidenemalonitirile - "tear gas": a unique exposure outcome unmasked by strenuous exercise after a military training event. Mil Med 2002;167:136-9.

16 Hu H, Fine J, Epstein P, et al. Tear gas-harassing agent or toxic chemical weapon? JAMA 1989;262:660-3.

17 Himsworth $\mathbf{H}$, et al. Report of the inquiry into the medical and toxicological aspects of CS (ortho-chlorobenzylidine malononitrile). Part I. Enquiry into the medical situation following the use of CS in Londonderry on 13 and 14 August, 1969. London: HMSO, 1971

18 Himsworth $\mathrm{H}$, et al. Report of the inquiry into the Medical and Toxicological aspects of CS. Part II. Enquiry into toxicological aspects of CS and its use for civil purposes. London: HMSO, 1971.

19 Anonymous. TOMES Plus" $¥$ System, Micromedex Inc, Englewood, Colorado, vol 98, exp 30/6/98. Hygienic guide series. Methyl isobutyl ketone. American Industrial Hygiene Journal 1966;27:209-211.

20 Hathaway GJ, Proctor NH, Hughes JP. Proctor and Hughes-chemical hazards of the workplace. 4th ed. New York: Van Nostrand Reinhold, 1996.

21 Clayton GD, Clayton FE, eds. Patty's industrial hygiene and toxicology. 4th ed. New York: Wiley, 1994.

22 Department of Health. Committee on toxicity, mutagenicity and carcinogenicity of chemicals in food, consumer products and the environment. Statement on 2-chlorobenzylidene malononitrile (CS) and CS spray. London: Department of Health, 1999.

23 Wright S. An Appraisal of technologies of political control. A working document prepared for the European Parliament by the Scientific and Technological Options Assessment (STOA) Programme. Strasbourg: European Parliament, 6 Jan 1998.

24 Kock E, Rix R. A review of police trials of the CS aerosol incapacitant. Police Research Series, Paper 21. London: Police Research Group, 1996.

25 Hennekens $\mathrm{CH}$, Buring JE. Epidemiology in medicine. Toronto: Little, Brown, 1987. 